Research Article

\title{
Seismic Design Method of Self-Centring-Segment Bridge Piers with Tensile-Type Viscoelastic Dampers
}

\author{
Huixing Gao ${ }^{D},{ }^{1}$ Yang Song, ${ }^{1}$ Wenting Yuan, ${ }^{2}$ Hongxu Lu, ${ }^{1}$ and Shuo Cao ${ }^{1}$ \\ ${ }^{1}$ School of Transportation Science and Engineering, Jilin Jianzhu University, Changchun 130118, China \\ ${ }^{2}$ State Key Laboratory for Geomechanics \& Deep Underground Engineering, School of Mechanics and Civil Engineering, \\ China University of Mining and Technology, Xuzhou 221116, China \\ Correspondence should be addressed to Huixing Gao; gaohuixing@jlju.edu.cn
}

Received 25 November 2020; Revised 2 May 2021; Accepted 7 August 2021; Published 17 August 2021

Academic Editor: Quoc-Bao Bui

Copyright (c) 2021 Huixing Gao et al. This is an open access article distributed under the Creative Commons Attribution License, which permits unrestricted use, distribution, and reproduction in any medium, provided the original work is properly cited.

This paper aims to study the deformational behaviour of tensile-type viscoelastic dampers under different earthquake excitation directions. A method for calculating the corresponding equivalent additional stiffness and damping of a self-centring-segment bridge pier is derived. Using the displacement-based seismic design method, a design method for self-centring-segment bridge piers with tensile-type viscoelastic dampers is proposed. Using the proposed method, a self-centring-segment bridge pier is designed. Based on dynamic analysis of the finite element model by OpenSees, the effectiveness of the proposed seismic design method is validated.

\section{Introduction}

Priestly et al. $[1,2]$ first proposed the concept of employing unbounded post-tensioned tendons in RC structures in 1993. Since then, several theoretical, experimental, and analytical studies have been performed to investigate the self-centring properties of concrete piers with unbonded prestressed tendons under earthquake excitation. For example, Hewes [3] studied the pseudo-static response of precast-segment bridge piers. By simplifying the bending moment-curvature relationship of the bottom section of the precast-segment concrete bridge pier, the corresponding response expression of the shearing force at the pier bottom and displacement at the pier top were established. Furthermore, Dawood et al. [4] developed a numerical model of a half-scaled pier structure suffering from pseudo-static loading based on the geometric and material symmetry characteristics of precast-segment bridge piers.

In view of the complex mechanical properties of precastsegment bridge pier joints, some researchers have carried out related numerical simulation studies on the joints, compared the results with experimental data, and obtained good simulation results. Sideris [5] used Abaqus to simulate the hysteretic performance of precast-segment bridge piers with slide-opening joints and conducted a comparative analysis of the simulation results and experimental data, and the correctness of the finite element simulation results was verified. Kurama $[6,7]$ proposed a mechanical model of the nonlinear bending performance of a precast-segment assembled shear wall with unbonded prestressed bars, and the model established by this method was used for parameter analysis to verify the correctness of the theoretical formula of shear-wall resistance.

Due to the weakness of seismic energy dissipation in precast-segment bridge piers, many researchers have carried out research on vibration-control technology for these piers. Roh and Reinhorn [8] installed shape memory alloys (SMAs) between the foundation and pier segments as energy dissipation devices for precast-segment bridge piers. In this way, precast-segment bridge piers could achieve a better hysteretic energy dissipation capacity, and the seismic performance of precast-segment bridge piers was improved accordingly. Hung et al. [9] set RC shear keys between the precast-segment bridge column that were reinforced by energy-consuming steel bars to increase the pier's shear bearing capacity and integrity, and compared its hysteretic 
performance with that of cast-in-place RC piers. The experimental results showed that the residual displacement of the precast-segmental bridge column decreased with increasing prestress, and the displacement ductility also decreased. Wang et al. [10] conducted a hysteretic analysis of precast-segment bridge columns with planar joints and shear joints. The precast-segment bridge column models were not equipped with energy dissipation steel bars. The analytical results indicated that the type of surface joint did not affect the horizontal bearing capacity of the pier. However, shear resistance is beneficial for increasing the ductility and self-centring capability of precast-segment bridge columns. Mitoulis and Rodriguez Rodriguez [11] proposed a novel resilient hinge. This structure dissipates energy through the yielding of easily replaceable steel bars to provide rapid restoration times, thus being cost-effective and undergoing minimal damage during earthquakes. Rele et al. [12] proposed a novel resilient controlled-rocking bridge pier foundation. This structure demonstrated a high level of energy dissipation in the form of superelastic hysteresis and controlled the movements of piers subjected to relatively high seismic excitation.

Regarding the theoretical research of precast-segment bridge piers, many scholars have carried out a series of studies on the seismic performance of precast-segment bridge piers. $\mathrm{Ou}$ et al. $[13,14]$ analysed the moment-curvature relationship of the pier bottom section, and the correctness of the simplified analysis model was verified by numerical simulation. Kowalsky and Priestley. [15] proposed a methodology to calculate the shear strength of precast-segment concrete piers. Based on the geometric and material symmetry characteristics of precast-segment bridge piers, Wang et al. $[16,17]$ established an equivalent plastic hinge model of posttensioning precast-segment ultrahigh-performance concrete bridge columns and discussed the influences of seven related parameters on the energy dissipation and self-centring capacity of the piers. They proposed a new quantitative design criterion for the selfcentring capacity of precast-segment ultra-high-performance concrete bridge piers and established a fine numerical model. Based on the results of relevant parameter analysis, a simplified formula was established to evaluate the residual displacement. Do et al. [18] carried out a numerical study on the impact of precast-segment concrete columns with unbonded prestressed tendons in vehicle collisions, established a corresponding experimental model, and discussed the effects of precast-segment concrete piers, considering the prestressing level, number of segments, concrete strength, and vehicle speed. Guo et al. [19] pointed out that selfcentring bridge piers with inherent hysteretic energy dissipation capacities that are too low are prone to generating excessive displacement responses under rare earthquakes, and excessive displacement responses of bridge piers cause serious damage to the pier body, which leads to the failure of the bearing, large movements of the superstructure, and even the failure of the beam.

The direct displacement-based method is a widely used method in seismic design. It is simple and widely applicable and can be used for quick and efficient design. However, few papers have applied the displacement-based method in the vibration control of self-centring-segment bridge piers with viscoelastic dampers. This paper aims to study the deformational behaviour of tensile-type viscoelastic dampers under different earthquake excitation directions, and a method for calculating the corresponding equivalent additional stiffness and damping of the self-centring-segment bridge pier is derived. Using the displacement-based seismic design method, a seismic design method for a self-centring precast-segment bridge pier with a tensile-type viscoelastic damper is established. The seismic design of a self-centring precast-segment pier is carried out by this method, and dynamic analysis by the OpenSees finite element model verifies the effectiveness of the proposed design method.

\section{Equivalent Additional Stiffness and Damping Ratio of Tensile-Type Viscoelastic Dampers}

It is well-known that self-centring bridge piers generally sustain small structural damage owing to the noncontinuous joint between the piers and foundation and the post-tensioned tendons. However, this type of structure has very narrow, flag-shaped hysteretic characteristics, achieving a minor level of hysteretic damping under seismic excitation. To increase the damping of the structures, viscoelastic dampers are proposed to be employed as external dissipaters.

2.1. Mechanical Model of the Tensile-Type Viscoelastic Damper. The installation scheme and mechanical mechanism of viscoelastic dampers adopted in this paper have been described in detail in the literature [20]. Figure 1 shows a schematic diagram of a common self-centring bridge pier equipped with post-tensioned tendons. It is observed that this configuration of the energy-dissipation device is similar to conventional viscoelastic dampers with several sandwiched layers of viscoelastic material and steel plates. Oneway hinges are set at both ends of the damper. The installation scheme of the damper attached to the pier is depicted in Figure 1. It is observed that the viscoelastic dampers are installed at the bottom of the piers. One hinge is connected to the foundation, and the other is fixed on the column.

Figure 1 shows that the viscoelastic dampers sustain the axial tension force only if the earthquake ground motion propagates along the longitudinal direction owing to the function of the hinges. In this case, the viscoelastic material between the outer steel flanges and the centre plate is subjected only to pure shear deformation under external earthquake ground motions. However, if the earthquake excitation attacks the bridge structure along the transverse direction, the viscoelastic damper moves together with the deformation of the pier, resulting in torsion of the viscoelastic material between the inner and outer steel plates.

Viscoelastic dampers exhibit linear stiffness and viscous damping characteristics under external reciprocating loads. When the damper is installed on the self-centring precast segment of the pier, additional stiffness and damping will be provided to the precast-segment pier. Therefore, the 


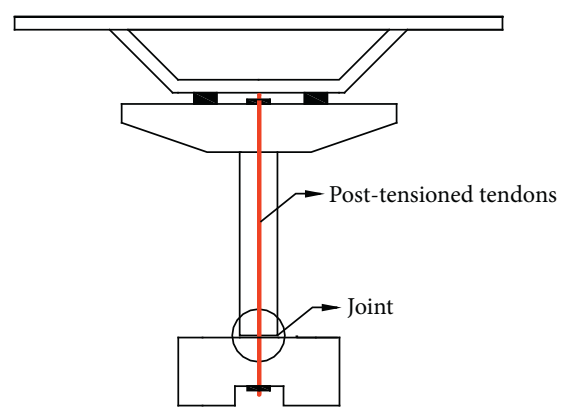

(a)

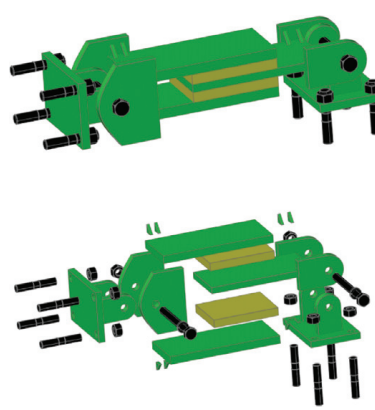

(b)

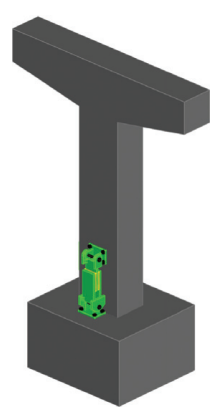

(c)

FIGURE 1: Schematic diagram of the self-centring bridge pier: (a) common self-centring bridge with post-tensioned tendons; (b) configuration of the viscoelastic damper; (c) installation scheme of the viscoelastic dampers.

additional stiffness and damping provided by the viscoelastic damper to the precast-segment pier needs to be estimated, which will provide the foundation for the rational design of a mixed pier structure.

According to the installation method mentioned above, the viscoelastic dampers of self-centring-segment bridge piers are subjected to the condition of pure tensile deformation, and the corresponding force-displacement relationship of viscoelastic dampers can be described as follows:

$$
F(t)=k_{F} x_{F}(t)+c_{F} \dot{x}_{F}(t),
$$

where $F(t)$ is the control force generated by the viscoelastic damper; $K_{F}$ and $C_{F}$ are the equivalent stiffness and equivalent damping of viscoelastic dampers, respectively; and $x_{F}(t)$ and $\dot{x}_{F}(t)$ are the relative displacement and relative velocity between the inner and outer steel plates, respectively.

$k_{F}$ and $c_{F}$ in the formula are calculated as follows:

$$
\left\{\begin{array}{l}
k_{F}=\frac{n A G^{\prime}(\omega)}{h}, \\
c_{F}=\frac{n A G^{\prime \prime}(\omega)}{\omega h},
\end{array}\right.
$$

where $n$ is the number of layers of viscoelastic materials; $G^{\prime}(\omega)$ and $G^{\prime \prime}(\omega)$ are the energy storage modulus and loss modulus of the viscoelastic materials, respectively; and $A$ and $h$ are the area and thickness of the viscoelastic material between the inner and outer steel plates, respectively.

As shown in Figure 1, when seismic excitation acts along the longitudinal direction of the pier, the viscoelastic damper is subjected to axial tension due to the action of a unidirectional hinge, and the interaction mode between the viscoelastic damper and the structure is shown in Figure 2. According to the deformation relationship between the precast-segment concrete pier and viscoelastic damper, the axial deformation of the damper can be expressed as follows:

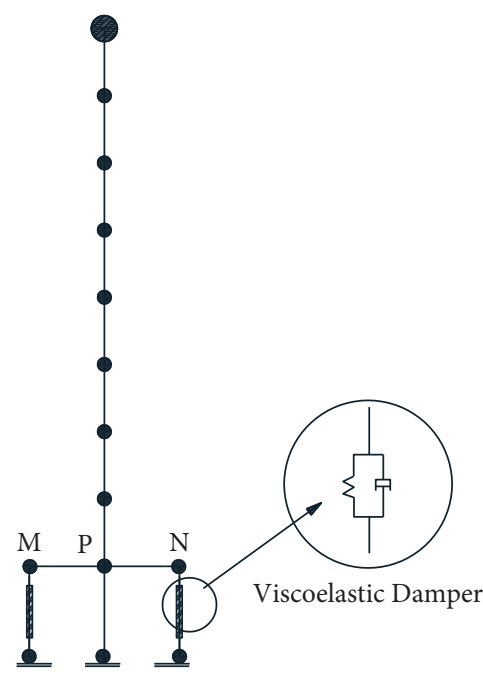

(a)

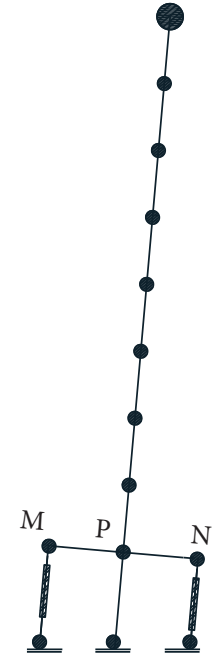

(b)
Figure 2: Mechanical model of the tensile-type viscoelastic dampers: (a) without deformation; (b) with deformation.

$$
\left\{\begin{array}{l}
a_{M}=y_{p} \cos \theta_{p}+\frac{B}{2} \sin \theta_{p} \\
a_{N}=y_{p} \cos \theta_{p}-\frac{B}{2} \sin \theta_{p},
\end{array}\right.
$$

where $a_{M}$ and $a_{N}$ are the corresponding axial deformations of the viscoelastic dampers; $y_{p}$ is the vertical displacement of pier point $P ; B$ is the width of the pier; and $\theta_{p}$ is the angle at point $P$ on the pier.

Thus, under these conditions, the control force produced by viscoelastic dampers is

$$
\left\{\begin{array}{l}
F_{M}=\frac{n G^{\prime}(\omega) A}{h} a_{M}+\frac{n G^{\prime \prime}(\omega) A}{\omega h} \dot{a}_{M}, \\
F_{N}=\frac{n G^{\prime}(\omega) A}{h} a_{N}+\frac{n G^{\prime \prime}(\omega) A}{\omega h} \dot{a}_{N} .
\end{array}\right.
$$

Because of the rotation of the hinges, when the pier deforms in the horizontal direction, it does not exert a force on the damper. The vertical deformation of the 
structure exerts a vertical tension force on the pier, but the bending moments generated by the vertical tension of the two dampers cancel each other out. The horizontal and vertical components on the dampers generated by pier rotation cancel each other out under the arrangement of symmetrical dampers, only producing a bending moment effect. Considering the offsetting effect of the symmetrical dampers, the control forces of dampers under horizontal, vertical, and rotational deformations are decomposed, and the force acting on the pier with a single viscoelastic damper under slight structural deformation is as follows:

$$
\left\{\begin{array}{l}
F_{P x}=0, \\
F_{P y}=\frac{n G^{\prime}(\omega) A}{h} y_{p}+\frac{n G^{\prime \prime}(\omega) A}{\omega h} \dot{y}_{p}, \\
M_{P \theta}=\frac{n G^{\prime}(\omega) A}{h}\left(\frac{B^{2}}{2} \theta_{p}\right)+\frac{n G^{\prime \prime}(\omega) A}{\omega h}\left(\frac{B^{2}}{2} \dot{\theta}_{p}\right) .
\end{array}\right.
$$

\subsection{Equivalent Additional Stiffness and Equivalent Additional} Damping Ratio. For the mechanical model of a stretching viscoelastic damper based on the above subsections, under the action of symmetrically arranged viscoelastic dampers, formula (5) gives the control forces generated by the precastsegment concrete pier. Formula (5) shows that under this condition, the horizontal force generated by the damper is zero, the vertical force does not cause horizontal deformation of the structure, and the deformation of the structure is affected only by the bending moment. Figure 3 shows the equivalent mechanical model of the tensile-type viscoelastic damper acting on the precast-segment pier. The control force of the viscoelastic damper at point $P$ of the pier will cause lateral deformation in different parts of the structure. Ignoring the influence of horizontal and vertical forces, the bending moment produced by the damper can be obtained by graph multiplication, and the geometric deformation relationship between pier point $P$ and pier top point $A$ can be expressed as

$$
\left\{\begin{array}{l}
x_{P}=\frac{r}{L-r} x_{A}, \\
\theta_{P}=\frac{1}{L-r} x_{A},
\end{array}\right.
$$

where $L$ is the pier height, $r$ is the length from the centre of the damper to the bottom of the pier, and $2 r$ is the height from pier point $P$ to the pier bottom.

Assuming a virtual equivalent horizontal force is acting on the top of the pier, the horizontal deformation at the pier top is equal to the horizontal deformation caused by the control force of the viscoelastic damper acting on point $P$ of the pier, and the equivalent horizontal force is as follows:

$$
F_{E A}=K_{v e} x_{A}+C_{v e} \dot{x}_{A}=\frac{6 r(L-r)}{L^{3}} M_{P \theta},
$$

where $K_{v e}$ and $C_{v e}$ are the equivalent additional stiffness and additional damping of the viscoelastic dampers, respectively, and $x_{A}$ and $\dot{x}_{A}$ are the horizontal displacement and horizontal velocity at point $\mathrm{A}$ of the pier top, respectively.

By substituting formulas (5) and (6) into formula (7), the following is obtained:

$$
\beta_{1}=\frac{3 B^{2} r}{L^{3}} .
$$

Then, the additional stiffness and additional damping provided by the stretch-type viscoelastic damper to the precast-segment bridge piers can be obtained as

$$
\left\{\begin{array}{l}
K_{v e}=\beta_{1} \frac{n G^{\prime}(\omega) A}{h}, \\
C_{v e}=\beta_{1} \frac{n G^{\prime \prime}(\omega) A}{\omega h} .
\end{array}\right.
$$

After installing viscoelastic dampers, the equivalent damping ratio of precast piers, which are made up of controlled segments, is composed of structural damping from the pier and additional damping from the dampers. Therefore, the equivalent additional damping ratio and the total damping ratio of the structure provided by the viscoelastic dampers to the assembled pier can be expressed as

$$
\begin{aligned}
& \xi_{v e}=\frac{C_{v e} \omega_{0}}{2\left(K_{v e}+K_{P}\right)}, \\
& \xi_{e q}=\xi_{s}+\xi_{v e},
\end{aligned}
$$

where $\xi_{s}$ is the damping ratio of the pier structure; $\xi_{v e}$ is the equivalent additional damping ratio provided by the viscoelastic dampers; $\xi_{e q}$ is the total equivalent viscous damping ratio of the controlled structure; $K_{P}$ is the equivalent linear stiffness of precast-segment concrete piers; and $\omega_{0}$ is the natural frequency of the controlled structure.

\section{Seismic Design Method for Precast-Segment Bridge Piers with External Tensile-Type Viscoelastic Dampers}

3.1. Seismic Design Method for Hybrid Bridge Structures. Based on the seismic design method of the conventional selfcentring precast-segment pier developed in the literature [21], a corresponding seismic design method for a selfcentring-segment pier with a viscoelastic damper is proposed. The design method adopts the displacement-based design concept, and the main procedures are as follows:

(1) Determining the parameters of the self-centring precast-segment pierDetermining the design parameters of the segment pier initially mainly considers the pier section size, column height, selfweight of the superstructure, material properties of 


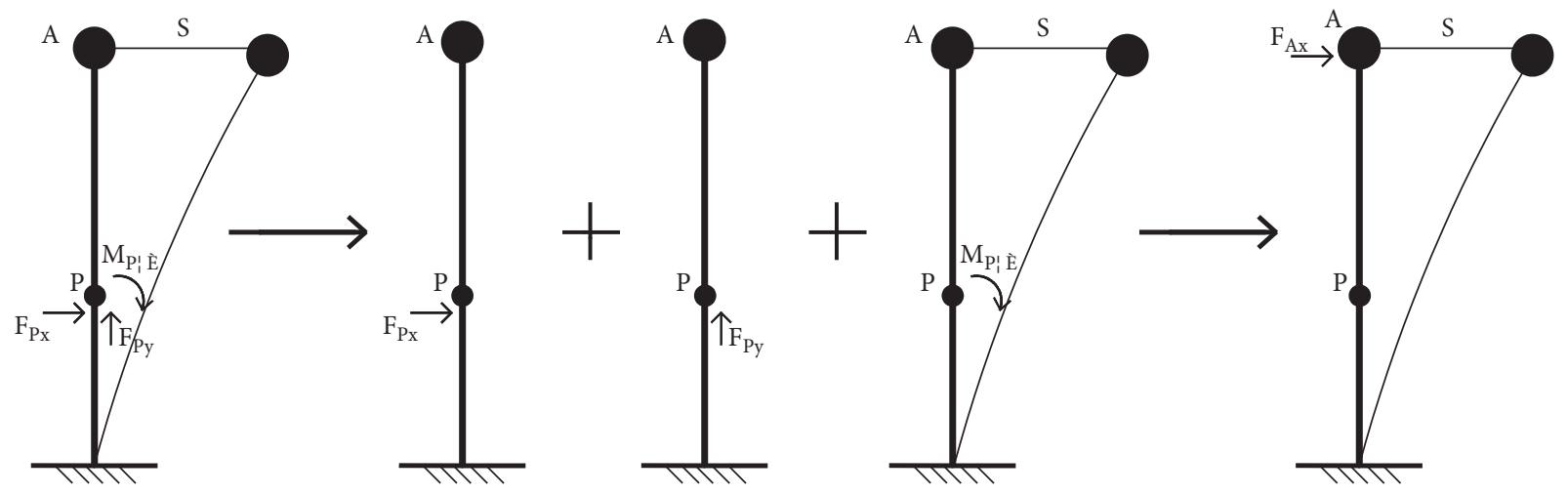

FIgURE 3: Equivalent mechanical model of the tensile-type damper.

the concrete, post-tensioning reinforcement, viscoelastic damper parameters, etc.

(2) Determining the target displacement:The desired value of $t$ displacement of the bridge pier that impacts the design ground motion is mainly determined by the repairability and importance of the bridge after an earthquake. Usually, this value can be taken as the corresponding displacement between $1.0 \%$ and $2.0 \%$ of the displacement angle of the pier.

(3) Estimating the equivalent viscous damping of the structural system:After installing the viscoelastic damper, the damper further provides additional damping to the structure. The nonlinear hysteretic damping of self-centring structures can be calculated by the hysteretic loop curve obtained from the nonlinear analysis of the structure [16] and the calculation method for the additional damping from viscoelastic dampers based on the method derived in the previous section.

(4) Determining the effective viscous damping:The equivalent viscous damping ratio is the damping ratio corresponding to the precast-segment pier when the pier reaches the target displacement under the action of ground motion, but the horizontal displacement amplitude of the pier top is mostly smaller than the target displacement under the action of ground motion. The corresponding equivalent damping ratio of the structure is also smaller than the equivalent viscous damping ratio calculated under the condition of target displacement. To correct for this effect, the use of the modification factor $\beta$ of viscous damping to modify the equivalent viscous damping ratio and determine the effective viscous damping ratio of the structure is proposed in the literature [21]. The empirical formula for the modification factor $\beta$ of the viscous damping of the assembled pier is as follows:

$$
\begin{aligned}
\hat{\xi}_{e q} & =\beta \xi_{\text {eq }}, \\
\beta & =\left(0.55+0.12 \mu_{\Delta}\right),
\end{aligned}
$$

where $\mu_{\Delta}$ is the ductility coefficient.
(5) Modify the design displacement response spectrumThe seismic design based on displacement needs to use the displacement design spectrum to determine the displacement response of the structure under the condition of the design ground motion. This paper adopts the AASHTO specification [22] to design the displacement response spectrum, which can be expressed as

$$
S_{d-5 \%}=\frac{1.2}{4 \pi^{2}} A S g T^{4 / 3} \leq \frac{2.5}{4 \pi^{2}} A g T^{2}
$$

where $S_{d-5 \%}$ is the design spectral displacement for 5 percent viscous damping; $A$ is the acceleration coefficient, which is equal to the peak ground acceleration with a 10 percent probability of being exceeded in 50 years; $g$ is the gravitational constant; and $S$ is the site coefficient.

Since formula (12) is the design displacement response spectrum when the damping ratio is $5 \%$, in the case of a large damping ratio, the reaction spectrum needs to be modified. According to EUROCODE8 [23], the response spectrum of the modified design displacement considering the influence of a large damping ratio can be expressed as

$$
S_{d-\hat{\xi}_{e q}}=\sqrt{\frac{7}{2+100 \hat{\xi}_{e q}}} S_{d-0.5} .
$$

Substituting formula (13) into (12) yields

$S_{d-\hat{\xi}_{e q}}=\sqrt{\frac{7}{2+100 \hat{\xi}_{e q}}} \frac{1.2}{4 \pi^{2}} A S g T^{4 / 3} \leq \sqrt{\frac{7}{2+100 \hat{\xi}_{e q}}} \frac{2.5}{4 \pi^{2}} A g T^{2}$.

(6) Estimate the equivalent period of vibration:The period of vibration of an equivalent linear system can be estimated from the modified design displacement response spectrum, as shown in Figure 4. The period corresponding to the target displacement in the figure is the structural equivalent period. 


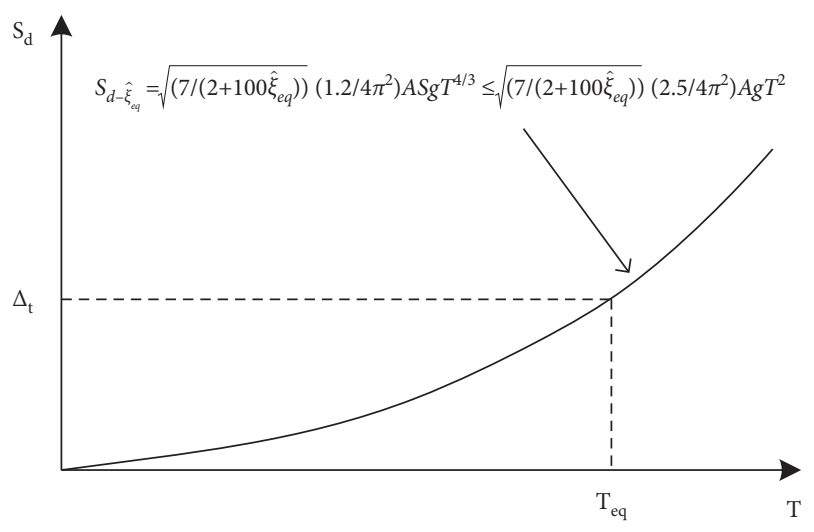

FIgURE 4: Determined method of the equivalent period of the structure.

(7) Calculate the equivalent stiffnessThe structure is equivalent to an SDOF structure, and the equivalent stiffness can be determined as

$$
K_{e q}=4 \pi^{2} \frac{m_{p}}{T_{e q}^{2}}
$$

where $m_{p}$ is the total mass of the pier, including the weight of the superstructure and self-weight of the pier.

(8) Calculate the seismic force at the target displacement: According to the target displacement of the structure, the seismic inertial force generated by the horizontal lateral deformation can be calculated by the following formula:

$$
F_{t}=K_{e q} \Delta_{t} .
$$

(9) Determine the reinforcement ratio:The reinforcement ratio of the pre-stressed steel bar of the pier is calculated according to the target displacement and corresponding load of the precast-segment pier, such that the structure will not overturn under the action of earthquakes.

(10) Check the section size of the viscoelastic damper: To meet the design requirements, according to the equivalent additional damping ratio and performance parameters of the structure provided by the viscoelastic materials, the section size of the viscoelastic damper is checked. Following these steps, an iterative design is needed if the requirements are not met.

3.2. A Design Example of a Hybrid Pier Structure. A selfcentring precast-segment bridge pier with a viscoelastic damper is designed by the displacement-based seismic design method, and the method is verified by dynamic timehistory analysis. The design steps are as follows:

(1) Defining parameters of the mixed pier:The schematic figure of the bridge is shown in Figure 5. The bridge has a span of $40 \mathrm{~m}$. The width and height are
$14.0 \mathrm{~m}$ and $2.0 \mathrm{~m}$, respectively. The load from the superstructure is $200 \mathrm{kN} / \mathrm{m}$. The clear height of the pier is $9.0 \mathrm{~m}$, the section size of the rectangular pier is initially set as $m$, the initial ratio of longitudinal reinforcement in the concrete bridge pier is set as $1.15 \%$, and the pier consists of 36 longitudinal bars with a diameter of $32 \mathrm{~mm}$. The diameter of the stirrups is $16 \mathrm{~mm}$, and the spacing is $160 \mathrm{~mm}$. Six $10 \times 140 \mathrm{~mm}^{2}$ strands with a yield strength and ultimate strength of $1680 \mathrm{MPa}$ and $1860 \mathrm{MPa}$, respectively, are used for prestressing tendons, and their reinforcement ratio is $0.33 \%$. The initial tensile stress of the strands is assumed to be $750 \mathrm{MPa}$. The mechanical properties of concrete and steel are listed in Table 1. According to the above parameters, the axial compression ratios of the self-weight of the superstructure and the prestressed steel bars are calculated to be $9.07 \%$ and $7.14 \%$, respectively.

The shear energy storage modulus and shear loss modulus of viscoelastic materials in the damper are selected as $2.0 \mathrm{MPa}$ and $3.0 \mathrm{MPa}$, respectively, and each viscoelastic damper contains two layers of viscoelastic material with a thickness of $10.0 \mathrm{~mm}$. The length and width of the viscoelastic damping material are initially set to $0.6 \mathrm{~m}$.

(2) Determine the target displacement:According to the functional requirements of the bridge, the target displacement of the bridge under design earthquake ground motion is determined to be $1.0 \%$ of the pier height:

$$
\Delta_{t}=0.01 L_{c}=0.01 \times(9+1) \mathrm{m}=100 \mathrm{~mm} .
$$

(3) Estimating the equivalent viscous damping ratio: The longitudinal input of the ground motion is taken as the control condition, and two symmetrical viscoelastic dampers are designed and installed on the inside (long side) of the pier section. Under this condition, the viscoelastic damper is represented as a tensile-type damper. The horizontal input of ground motion under the installation scheme is analysed and checked by time history analysis. According to formulas (8) and (9), the equivalent additional stiffness and equivalent additional damping ratio provided by the damper to the structure are $699.8 \mathrm{kN} / \mathrm{m}$ and $12.8 \%$, respectively. Upon setting up the preset finite element model of the self-centring precast-segment pier, according to hysteretic analysis, the hysteretic equivalent viscous damping ratio of the structure under the target displacement condition is $27.2 \%$. The two parts of damping are superimposed to obtain an equivalent viscous damping ratio of $40.0 \%$ for the assembled bridge pier after the damper is installed.

(4) Determining the effective viscous damping ratio: According to the hysteresis analysis of the bridge pier, the ultimate displacement and yield displacement of the structure are $108 \mathrm{~mm}$ and 


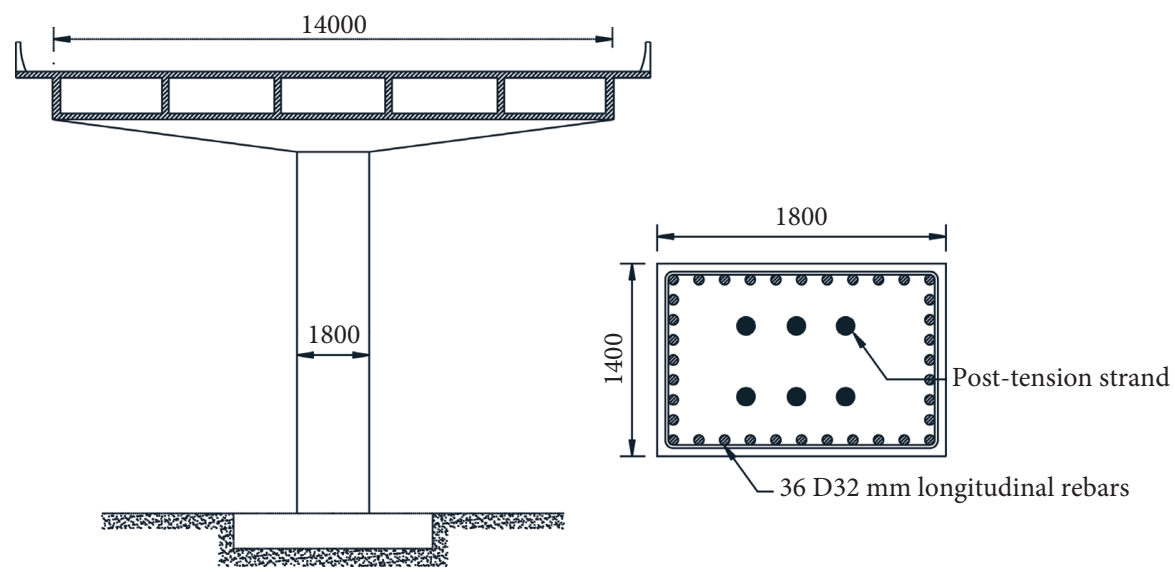

Figure 5: Schematic diagram of the bridge configuration and reinforcement.

TABLE 1: Material properties of the self-centring-segment bridge.

\begin{tabular}{|c|c|c|c|c|c|c|c|}
\hline \multicolumn{2}{|c|}{ Concrete } & \multicolumn{2}{|c|}{ Longitudinal reinforcement } & \multirow{2}{*}{$\begin{array}{l}\text { Stirrup } \\
\text { Yield } \\
\text { strength } \\
(\mathrm{MPa})\end{array}$} & \multicolumn{3}{|c|}{ Prestressed reinforcement } \\
\hline $\begin{array}{l}\text { The compressive } \\
\text { strength }(\mathrm{MPa})\end{array}$ & $\begin{array}{c}\text { Modulus of } \\
\text { elasticity (GPa) }\end{array}$ & $\begin{array}{c}\text { Yield } \\
\text { strength } \\
(\mathrm{MPa})\end{array}$ & $\begin{array}{c}\text { Modulus of } \\
\text { elasticity }(\mathrm{GPa})\end{array}$ & & $\begin{array}{c}\text { Yield } \\
\text { strength } \\
(\mathrm{MPa})\end{array}$ & $\begin{array}{c}\text { Ultimate } \\
\text { strength (MPa) }\end{array}$ & $\begin{array}{c}\text { Modulus of } \\
\text { elasticity (GPa) }\end{array}$ \\
\hline 35 & 30 & 375 & 200 & 286 & 1680 & 1860 & 195 \\
\hline
\end{tabular}

$33.5 \mathrm{~mm}$, respectively. Then, the effective viscous damping ratio of the controlled structure is obtained by formula (14):

$$
\hat{\xi}_{e q}=\left(0.55+0.12 \mu_{\Delta}\right) \xi_{e q}=\left(0.55+0.12 \times \frac{108}{33.5}\right) \times 0.40=0.375 .
$$

(5) Modifying the design displacement response spectrum:The seismic fortification intensity of the structure is 9 degrees. Under mild earthquakes, the PGA is $0.4 \mathrm{~g}$, and the site coefficient is 1.2 . Using the effective viscous damping ratio of the structure, the displacement spectrum under the condition of a $5 \%$ damping ratio is corrected according to formula (14):

$$
S_{d-\hat{\xi}_{\text {eq }}}=\sqrt{\frac{7}{2+100 \times 0.375}} \frac{1.2}{4 \pi^{2}} \times 0.4 \times 1.2 \times g T^{4 / 3} \leq \sqrt{\frac{7}{2+100 \times 0.375}} \frac{2.5}{4 \pi^{2}} \times 0.3 g T^{2}=6.15 \times 10^{-3} g T^{4 / 3} \leq 8.08 \times 10^{-3} g T^{2} .
$$

(6) Estimating the equivalent period of the structures: The equivalent period of the structure is the period corresponding to the target displacement of the top of the precast-segment pier. Therefore, upon substituting the target displacement of $0.1 \mathrm{~m}$ into the left side of formula (14), the equivalent period of the structure is calculated as $T_{e q}=1.44 \mathrm{~s}$.

(7) Calculating equivalent stiffness:The equivalent stiffness of the precast-segment pier can be determined by formula (15):

$K_{e q}=4 \pi^{2} \frac{m_{p}}{T_{e q}^{2}}=4 \pi^{2} \frac{200 \times 40 / 9.8}{1.44^{2}}=15217.7 \mathrm{kN} / \mathrm{m}$.

(8) Calculating the seismic inertial force corresponding to the target displacement:According to formula
(16), the seismic inertial force generated by the target displacement is calculated as follows:

$F_{t}=K_{e q} \Delta_{t}=15217.7 \times 0.10=1521.77 \mathrm{kN}$.

(9) Checking the reinforcement ratio of the prestressed bars in the pier:The lateral loads generated by earthquakes are balanced by the structural self-weight and the tension produced by the prestressed tendons. To protect the structure under the action of an earthquake, the overturning resistance shall be greater than the overturning moment generated by the earthquake excitation. Based on this principle, whether the reinforcement ratio of the prestressed steel bar meets the requirement can be checked. 


$$
\begin{aligned}
M & =\left(G_{P}+F_{p}\right) \times \frac{H}{2}=(200 \times 40+14112) \times \frac{1.4}{2}=15478.4 \mathrm{kN} . \mathrm{m} \\
& \geq F_{t} \times L=15217.7 \mathrm{kN} . \mathrm{m} .
\end{aligned}
$$

(10) Checking the section size of the viscoelastic damper: As seen from the design steps, the design meets the requirements under the selected viscoelastic material performance parameters and preset viscoelastic material section size, the section size of viscoelastic damper is qualified, and no iteration is required.

3.3. Time History Analysis. In this study, a hybrid system consisting of a self-centring bridge pier with a viscoelastic damper is analysed using the finite element method based on the OpenSees software application. A schematic diagram of the analytical model of the hybrid system is shown in Figure 6. Figures 6(a) and 6(b) show the finite element model of the common post-tensioned bridge pier. As shown in the figure, the self-centring pier can be modelled using the nonlinear beam-column element for the concrete column and the truss element for the tendons. In this study, the column section is defined with the fibre model using the material model Concrete02, which was developed based on the Kent-Scott-Park model [24], for unconfined covered concrete and confined-core concrete. The constitutive relationship of reinforcement is represented by the Steel02 material model based on the Giuffre-Menegotto-Pinto model [25]. For the unbonded tendons, initial stress is applied to the truss elements to model the initial tension force of the tendons. Owing to the constraints of the concrete, the lateral DOFs of the truss element are assumed to be coupled with the fibre element, whereas the longitudinal DOFs are free in the vertical direction. At the top of the pier, all nodal DOFs of the truss element are constrained to the node of the fibre element to model the anchorages of the post-tensioned tendons with the concrete column.

Because of the existence of the joint and critical section between the pier bottom and foundation of the rocking system, there is noncontinuity and incompatibility of the deformation at the opening interface. The effectiveness of the viscoelastic dampers installed at the bottom of the bridge pier is strongly related to the gap opening and the corresponding local deformation of the bridge structure. Therefore, to model the gap opening and the local deformation, the zero-length element is used in the finite element model. As shown in Figure 6, two rigid beam elements are set at the bottom of the column with lengths equalling half of the beam width. At the end of the rigid beam elements, zerolength elements are used to connect the beams and the foundations. An elastic material that tolerates only compression without tension is assigned to the zero-length element. Furthermore, to prevent the penetration of the column into the foundation, a large modulus of elasticity is set for the material of the zero-length elements.

Based on the finite element model of the common posttensioned bridge pier, an analytical model of the hybrid system with viscoelastic dampers that considers differences in the propagation direction of earthquake excitations and the deformation status of the viscoelastic dampers is also established. As shown in Figure 6, if the viscoelastic dampers sustain only pure shear deformation, the viscoelastic dampers can be easily modelled by the Kelvin model with the elastic spring and dashpot combined in parallel. In OpenSees, the Kelvin model can be represented by two truss elements with elastic and viscous materials. Using this method, the finite element model of the column with a viscoelastic damper is shown in Figure 6(c). In this model, it is also observed that two rigid beam elements are set to consider the installation location of the dampers. If the earthquake excites the structure in the transverse direction, which induces the translation and rotation of the viscoelastic dampers, the finite element model of the structure with viscoelastic dampers can be constructed using two zerolength elements, as shown in Figure 6(d), according to the mechanical model of the viscoelastic damper. In this case, one zero-length element with elastic materials is adopted to model the restoring force in the three different DOF directions. The other zero-length element uses viscous materials to model the damping forces. The stiffness and damping of the zero-length element can be determined as $\left(k_{F}, k_{F},\left(b^{2}+l^{2}\right) k_{F} / 12\right)$ and $\left(c_{F}, c_{F},\left(b^{2}+l^{2}\right) c_{F} / 12\right)$, respectively [20].

Based on the abovementioned finite element modelling method for self-centring-segment piers and piers with viscoelastic dampers installed, a finite element model of the designed structure is built in OpenSees software. Under the condition that the damper is installed inside the bridge pier, considering the seismic inputs along the longitudinal and transverse directions of the bridge, the control effect of the damper under tension and torsion deformation is analysed.

Northridge seismic waves [20] are adopted as the input ground motion, and the peak acceleration is adjusted to 620 gal for a 9-degree earthquake to perform time-history reaction analysis. Figure 7 shows the time-history response of the pier top displacement under the longitudinal and transverse inputs from the Northridge seismic wave. The maximum horizontal displacement and root-mean-square value of the top of precast-segment bridge pier under longitudinal seismic input are $11.5 \mathrm{~cm}$ and $3.7 \mathrm{~cm}$, respectively. After the installation of viscoelastic dampers, the maximum displacement and root-mean-square value of the pier top were reduced to $9.2 \mathrm{~cm}$ and $3.4 \mathrm{~cm}$, reflecting reductions of $20.0 \%$ and $8.1 \%$, respectively.

Although viscoelastic dampers are designed under longitudinal bridge seismic input control conditions, dampers can also provide energy dissipation and shock absorption under the action of transverse bridge seismic motion. It can be seen from the figure that the maximum displacement of the pier top under transverse seismic excitation is $12.8 \mathrm{~cm}$ for the uncontrolled precast-segment pier, exceeding the design target displacement requirement of $10.0 \mathrm{~cm}$. After installing the viscoelastic dampers, the maximum displacement is reduced to $9.8 \mathrm{~cm}$, which is a reduction of $23.4 \%$ for the precast-segment bridge pier. The 


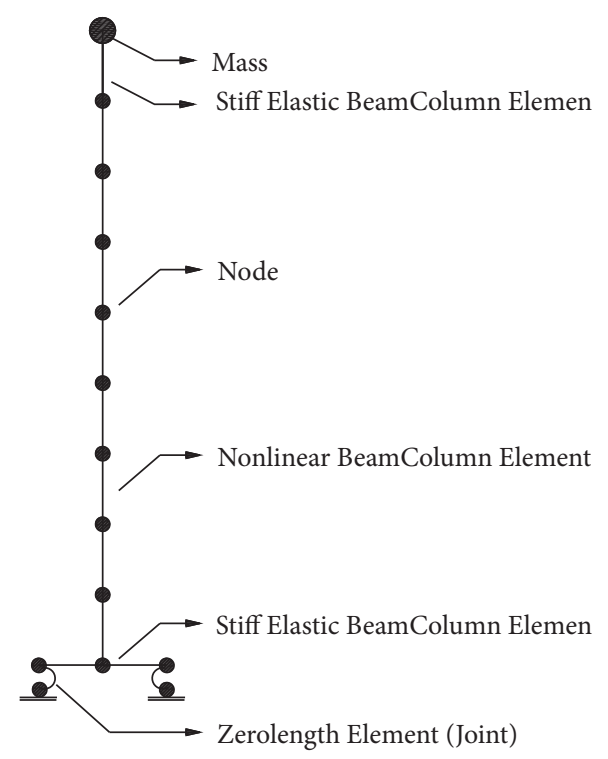

(a)
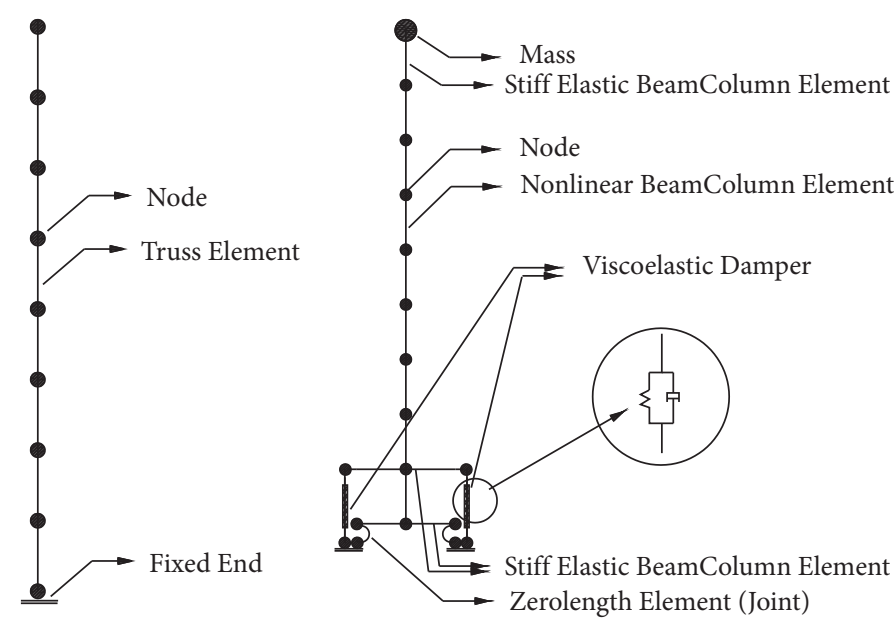

(b)

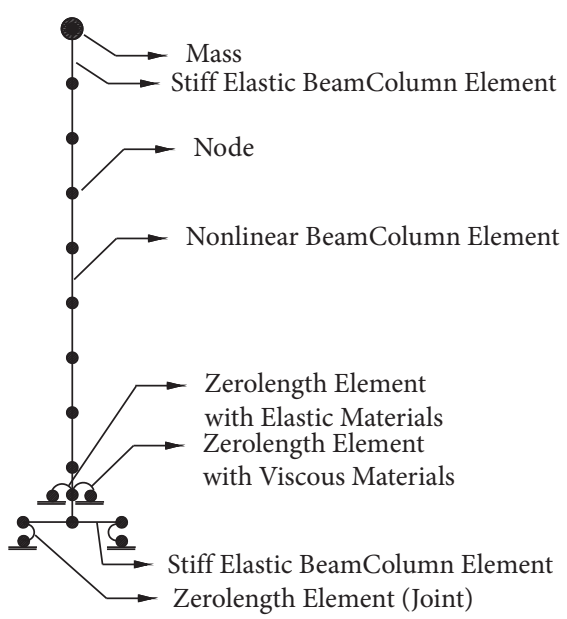

(c)

(d)

FIGURE 6: Schematic analytical model of the hybrid system: (a) column of a common self-centring pier; (b) tendons; (c) pier with viscoelastic dampers with longitudinal-direction deformation; (d) pier with viscoelastic dampers with transverse-direction deformation.

root-mean-square value of the pier top displacement also decreases from $3.5 \mathrm{~cm}$ to $2.6 \mathrm{~cm}$.

The time history curve of the shear force at the pier bottom is shown in Figure 8. As seen from the figure, the viscoelastic damper reduces the shear force on the precast-segment pier from $2598 \mathrm{kN}$ to $2113 \mathrm{kN}$ in the transverse direction, with a reduction ratio of $18.7 \%$. In the longitudinal direction, the shear force is decreased from $1774 \mathrm{kN}$ to $1565 \mathrm{kN}$, and the decrease ratio is $11.8 \%$. The shear force on the pier bottom obtained from dynamic time history analysis coincides with the seismic inertial force calculated in design step (8). Figure 9 shows the time history curve of the pier top acceleration. With the installation of viscoelastic dampers, the acceleration increases from $6.36 \mathrm{~m} / \mathrm{s}^{2}$ to $6.83 \mathrm{~m} / \mathrm{s}^{2}$ in the transverse direction and from $6.16 \mathrm{~m} / \mathrm{s}^{2}$ to $6.45 \mathrm{~m} / \mathrm{s}^{2}$ in the longitudinal direction. From the analysis results, it can be seen that the viscoelastic damper has no obvious effect on the pier top acceleration.

Figure 10 shows the tensile time history of the prestressed bars. As seen from the figure, after installing the viscoelastic damper, under the action of the longitudinal earthquake affecting the bridge, the maximum tension of the prestressed steel decreases from $7274 \mathrm{kN}$ to $7096 \mathrm{kN}$, with a reduction of $2.4 \%$. The maximum tension of the prestressed steel bar decreases from $8018 \mathrm{kN}$ to $7442 \mathrm{kN}$ under transverse seismic action, which is a reduction of $7.2 \%$. Figure 11 shows the time history of the opening width of the left joint at the pier bottom. After installing the viscoelastic damper, in the longitudinal and 


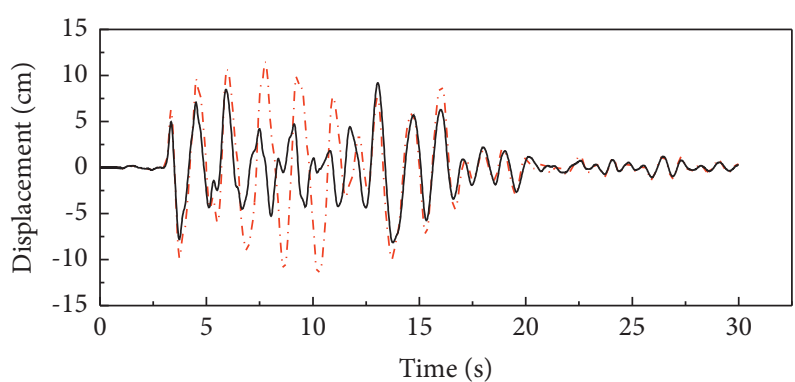

Without damper

- With damper

(a)

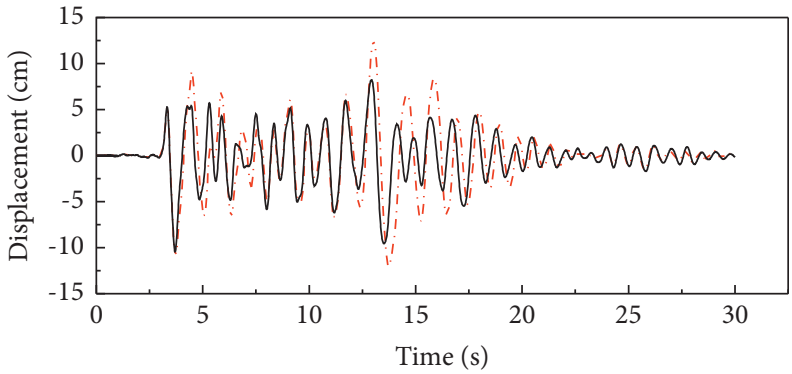

-.- Without damper

— With damper

FIgURE 7: Time histories of the top displacement: (a) longitudinal direction; (b) transverse direction.

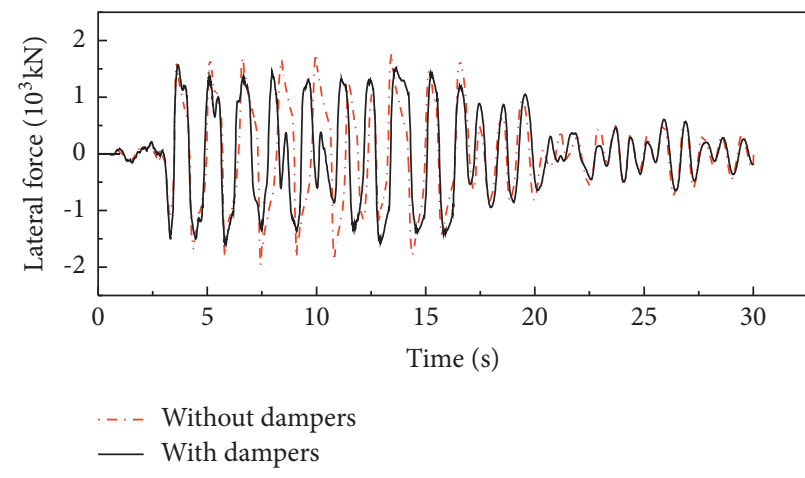

(a)

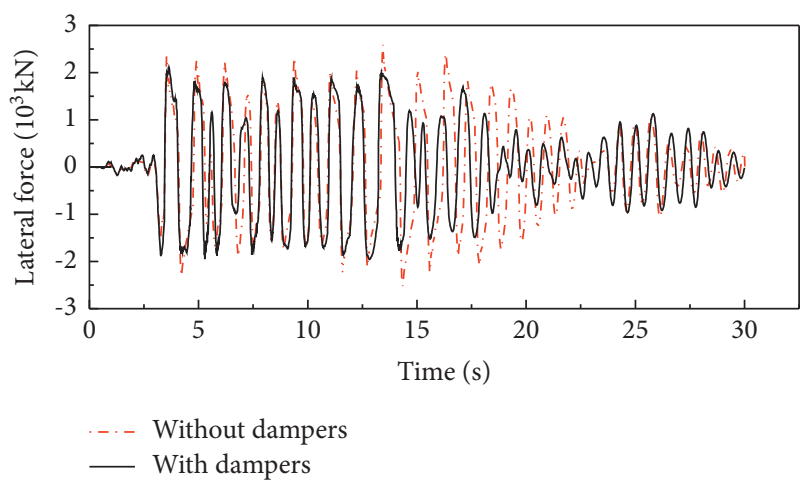

(b)

Figure 8: Time histories of the bottom shear: (a) longitudinal direction; (b) transverse direction.

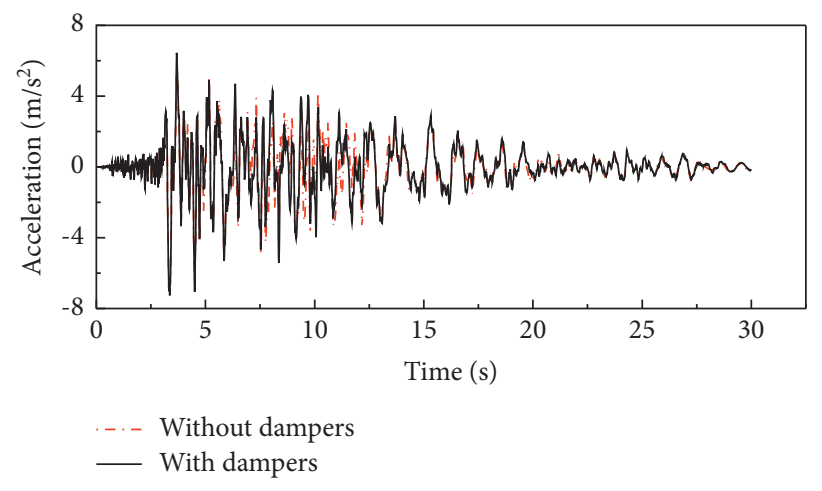

(a)

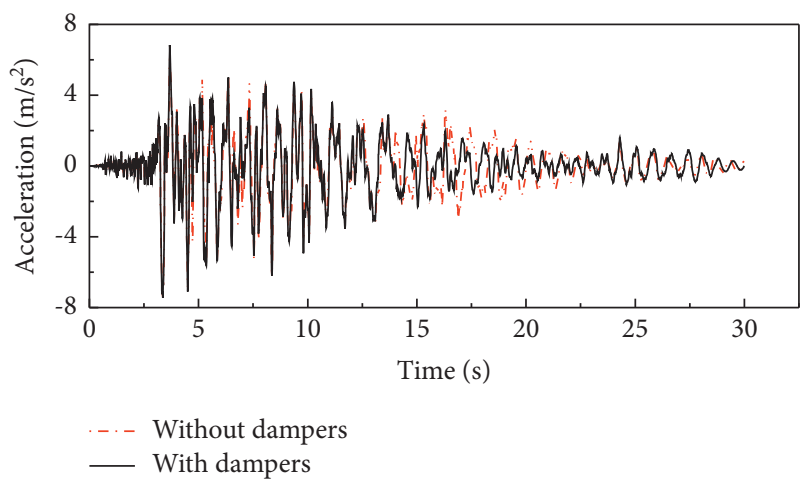

(b)

FIgURE 9: Time histories of the top acceleration: (a) longitudinal direction; (b) transverse direction. 


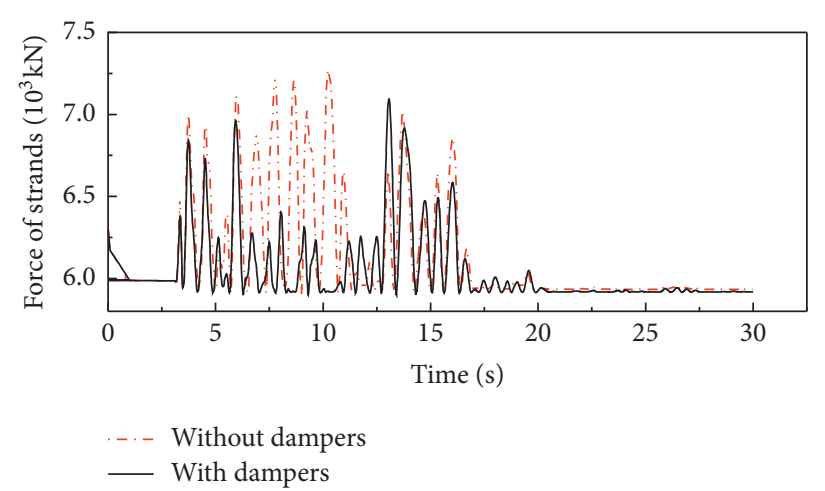

(a)

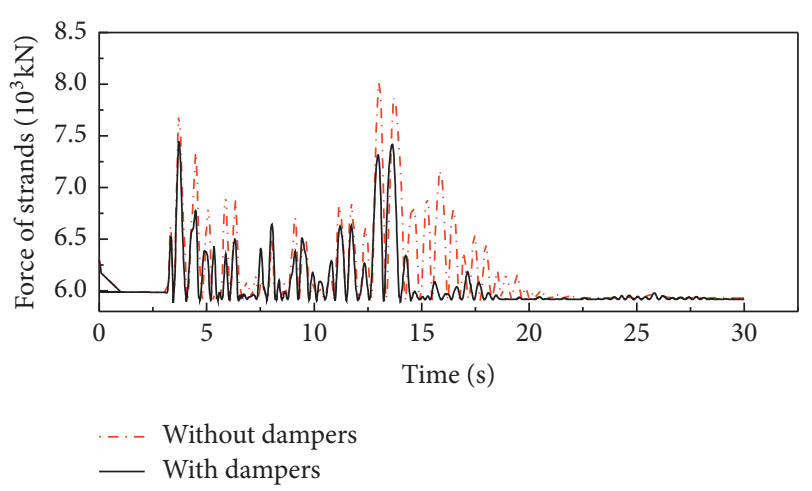

(b)

Figure 10: Tension force of the tendons: (a) longitudinal direction; (b) transverse direction.

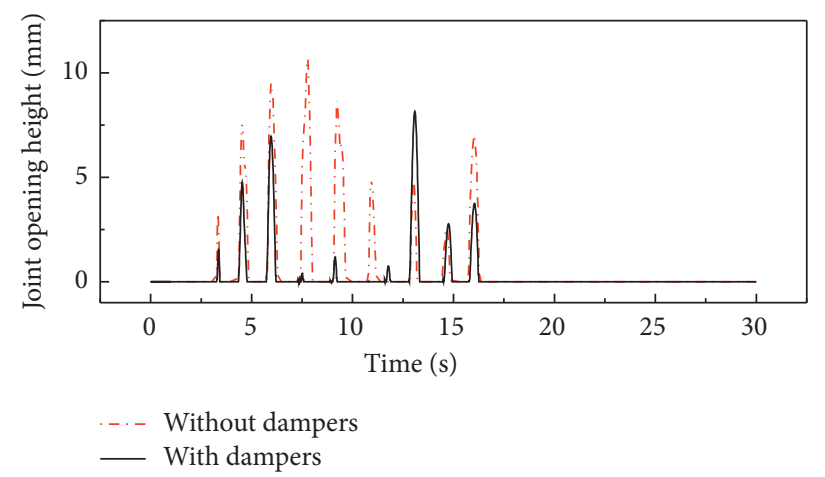

(a)

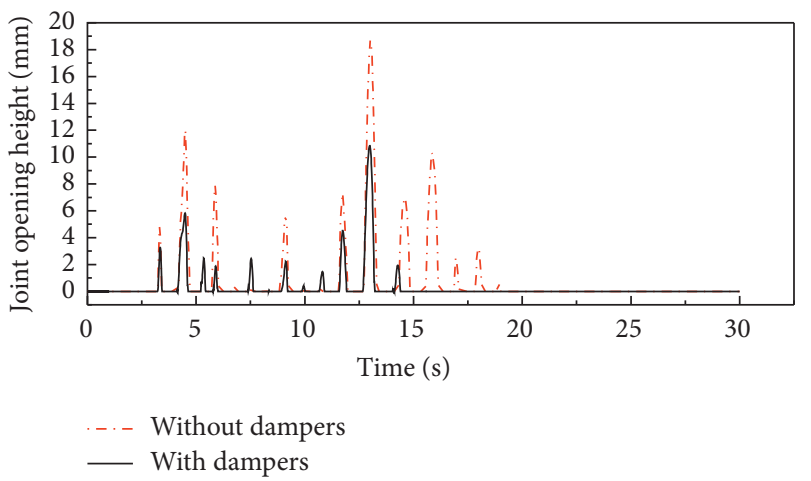

(b)

FIgURE 11: Opening height of the joint: (a) longitudinal direction; (b) transverse direction.

transverse directions, the maximum opening width of the left joint at the pier bottom is reduced from $10.7 \mathrm{~mm}$ to $8.2 \mathrm{~mm}$ and $18.7 \mathrm{~mm}$ to $10.8 \mathrm{~mm}$, respectively.

\section{Conclusions}

In this paper, the seismic design of self-centring precastsegment bridge piers with tensile-type viscoelastic dampers is studied. First, the calculation method for the equivalent additional stiffness and equivalent additional damping of the stretch viscoelastic damper is deduced. Then, through the displacement-based design concept, a seismic design method for a self-centring precast-segment bridge pier with a tensile-type viscoelastic damper is established. Finally, an example is given to verify the effectiveness of the proposed method. The main concluding remarks are as follows:

(1) Stretch-type viscoelastic dampers are installed on the self-centring bridge structure to provide additional stiffness and additional damping to the precastsegment pier. Establishing a simple and convenient method for calculating the equivalent additional stiffness and equivalent additional damping provides an important basis for the design of such structures.

(2) Performance-based design concepts are the development direction of seismic design theory. For self- centring precast-segment bridge piers with tensiletype viscoelastic dampers installed, according to the seismic design method based on displacement, effective structural designs can be realized.

(3) Through seismic design and dynamic time-history response analysis of a self-centring structure with tensile-type viscoelastic dampers, the validity of the design method is verified. The analysis results show that the effect of the tensile-type viscoelastic damper on the top displacement and bottom shear of the hybrid pier is obvious, but the effect of the pier top acceleration is not ideal.

\section{Data Availability}

The data used to support the findings of this study are available from the corresponding author upon request.

\section{Conflicts of Interest}

The authors declare no conflicts of interest.

\section{Acknowledgments}

This research was funded by the National Natural Science Foundation of China, grant no. 51222808, and the Education 
Department Science Foundation of Jilin Provincial of China, grant no. JJKH20210297KJ.

\section{References}

[1] M. J. N. Priestley, G. M. Calvi, and M. J. Kowalsky, Displacement Based Seismic Design of Structures, IUSS, Vienna, Austria, 2007.

[2] M. J. N. Priestley and J. R. Tao, "Seismic response of precast prestressed concrete frames with partially debonded tendons," PCI Journal, vol. 38, no. 1, pp. 58-69, 1993.

[3] J. T. Hewes, Seismic Design and Performance of Precast concrete Segmental Bridge Columns, University of California, Oak Land, CA, USA, 2002.

[4] H. Dawood, M. ElGawady, and J. Hewes, "Behavior of segmental precast posttensioned bridge piers under lateral loads," Journal of Bridge Engineering, vol. 17, no. 5, pp. 735-746, 2012.

[5] P. Sideris, Seismic Analysis and Design of Precast concrete Segmental Bridges, State University of New York at Buffalo, Buffalo, NY, USA, 2012.

[6] Y. C. Kurama, "Seismic design of unbonded post-tensioned precast concrete walls with supplemental viscous damping," Structural Journal, vol. 97, no. 4, pp. 648-658, 2000.

[7] Y. Kurama, R. Sause, S. Pessiki, and L.-W. Lu, "Lateral load behavior and seismic design of unbonded post-tensioned precast concrete walls," Structural Journal, vol. 96, no. 4, pp. 622-632, 1999.

[8] H. Roh and A. M. Reinhorn, "Hysteretic behavior of precast segmental bridge piers with superelastic shape memory alloy bars," Engineering Structures, vol. 32, no. 10, pp. 3394-3403, 2010.

[9] H.-H. Hung, Y.-C. Sung, K.-C. Lin, C.-R. Jiang, and K.-C. Chang, "Experimental study and numerical simulation of precast segmental bridge columns with semi-rigid connections," Engineering Structures, vol. 136, pp. 12-25, 2017.

[10] H.-L. Wang, S.-W. Liu, and Z. Zhang, "Seismic performance and effects of different joint shapes for unbonded precast segmental bridge columns," Journal of Mechanics, vol. 32, no. 4, pp. 427-433, 2016.

[11] S. A. Mitoulis and J. Rodriguez Rodriguez, "Seismic performance of novel resilient hinges for columns and application on irregular bridges," Journal of Bridge Engineering, vol. 22, no. 2, Article ID 04016114, 2017.

[12] R. R. Rele, R. Balmukund, S. A. Mitoulis, and S. Bhattacharya, "Rocking isolation of bridge pier using shape memory alloy," Bridge Structures, vol. 16, no. 2-3, pp. 85-103, 2020.

[13] Y.-C. Ou, M.-S. Tsai, K.-C. Chang, and G. C. Lee, "Cyclic behavior of precast segmental concrete bridge columns with high performance or conventional steel reinforcing bars as energy dissipation bars," Earthquake Engineering \& Structural Dynamics, vol. 39, no. 11, pp. 1181-1198, 2010.

[14] Y.-C. Ou, M. Chiewanichakorn, A. J. Aref, and G. C. Lee, "Seismic performance of segmental precast unbonded posttensioned concrete bridge columns," Journal of Structural Engineering, vol. 133, no. 11, pp. 1636-1647, 2007.

[15] M. J. Kowalsky and M. N. Priestley, "Improved analytical model for shear strength of circular reinforced concrete columns in seismic regions," Structural Journal, vol. 97, no. 3, pp. 388-396, 2000.

[16] Z. Wang, J. Wang, J. Zhu, G. Zhao, and J. Zhang, "Energy dissipation and self-centering capacities of posttensioning precast segmental ultra-high performance concrete bridge columns," Structural Concrete, vol. 21, no. 2, pp. 517-532, 2020.

[17] Z. Wang, J. Wang, G. Zhao, and J. Zhang, "Design criterion for the self-centering capacity of precast segmental UHPC bridge columns with unbonded post-tensioning tendons," Engineering Structures, vol. 200, Article ID 109706, 2019.

[18] T. V. Do, T. M. Pham, and H. Hao, "Numerical investigation of the behavior of precast concrete segmental columns subjected to vehicle collision," Engineering Structures, vol. 156, pp. 375-393, 2018.

[19] T. Guo, Z. Cao, Z. Xu, and S. Lu, "Cyclic load tests on selfcentering concrete pier with external dissipators and enhanced durability," Journal of Structural Engineering, vol. 142, no. 1, Article ID 04015088, 2016.

[20] A. Guo and H. Gao, "Seismic behavior of posttensioned concrete bridge piers with external viscoelastic dampers," Shock and Vibration, vol. 2016, Article ID 1823015, 12 pages, 2016.

[21] J. M. Wacker, D. G. Hieber, J. F. Stanton, and M. O. Eberhard, Design of Precast concrete Piers for Rapid Bridge Construction in Seismic Regions, Citeseer, Princeton, NJ, USA, 2005.

[22] Transportation Officials, Standard Specifications for Highway Bridges, AASHTO, Washington, DC, USA, 2002.

[23] Env CEN 1, Eurocode 8-Design of Structures for Earthquake Resistance-Part 1: General Rules, Seismic Actions and Rules for Buildings, CEN European Committee for Standardization, Brussels, Belgium, 1998.

[24] E. Spacone and F. C. Filippou, "Fiber beam-column model for non-linear analysis of RC frames: part I. formulation," Earthquake Engineering \& Structural Dynamics, vol. 25, pp. 711-725, 1996.

[25] L. P. Saenz, "Discussion of equation for the stress-strain curve of concrete," American Concrete Institute, vol. 9, pp. 12291235,1964 